\title{
Consolidating findings from business process change case studies using system dynamics: The example of employee morale
}

\author{
Zuzana Kristekova* \\ Chair for Information Systems \\ Technische Universität München, Germany \\ E-mail: zuzana.kristekova@in.tum.de
}

\section{Marlen C. Jurisch}

Chair for Information Systems

Technische Universität München, Germany

E-mail: marlen.jurisch@in.tum.de

\section{Michael Schermann}

Chair for Information Systems

Technische Universität München, Germany

E-mail: michael.schermann@in.tum.de

\section{Helmut Krcmar}

Chair for Information Systems

Technische Universität München, Germany

E-mail: krcmar@in.tum.de

*Corresponding author

\begin{abstract}
In this paper, we explore system dynamics as a useful approach to consolidate findings from case studies on business process change (BPC) projects. We compile data from $65 \mathrm{BPC}$ case studies to develop a system dynamics simulation model that helps us to investigate 'employee morale' as an important construct in BPC projects. We show that such simulation models consolidate the complex and often non-linear findings from BPC case studies in a way that makes it available to discourse among researchers, lecturers and students as well as BPC professionals. Thus, this paper contributes to knowledge management and learning by suggesting system dynamics as a valuable approach to illustrate and convey the complex relationships between important constructs in BPC. This paper also contributes to the domain of business process management by demonstrating the benefits of system dynamics as a way to review and consolidate the abundance of BPC case studies.
\end{abstract}

Keywords: Business process change; System dynamics; Learning; Employee morale; Meta-case analysis

Biographical notes: Zuzana Kristekova is a research associate and $\mathrm{PhD}$ student at the Chair for Information Systems at the Department of Informatics, 
Technische Universität München (TUM). She received her Diploma degree in computer science from TUM in 2008. Her research interests include modelling and simulating of complex systems, business process management, and elearning.

Marlen C. Jurisch is a research associate and $\mathrm{PhD}$ student at the Chair for Information Systems at the Department of Informatics, Technische Universität München (TUM). She holds a BA in International Business and an MA in Politics and Management. She spent time studying and researching abroad at the Shanghai Jiao Tong University and Centenary College of Louisiana. Her research interests include public information management, electronic government, business process change, and interorganizational networks.

Michael Schermann is a postdoctoral researcher of Information Systems at the Chair of Information Systems, Technische Universität München (TUM), Germany. He holds a master's degree in Information Systems from Technische Universität Dresden and a doctoral degree in Information Systems from the Technische Universität München. His research interests include IT-enabled management control systems, risk management, and project management. His work has appeared in Journal of Management Accounting Research, Wirtschaftsinformatik, and conferences such as the International Conference on Information Systems (ICIS).

Prof. Dr. Helmut Krcmar is a full professor of Information Systems and the dean of the Department of Informatics, Technische Universität München (TUM), since 2002. He worked as a Post Doctoral Fellow at the IBM Los Angeles Scientific Center, as assistant professor of Information Systems at the Leonard Stern School of Business, NYU, and at Baruch College, CUNY. From 1987 to 2002 he was Chair for Information Systems, Hohenheim University, Stuttgart. His research interests include information and knowledge management, service management, business process management, and information systems in health care and electronic government.

\section{Introduction}

Business process change (BPC) is a pivotal instrument for executives to improve business performance (Hammer \& Champy, 1993; Hill \& McCoy, 2011; Lopez, 2011). However, BPC projects present risky interventions, which are often fraught with uncertainties, frequent delays, and even failures (Hill \& McCoy, 2011). Research on BPC offers conflicting findings and suggests a complex and often non-linear nature of BPC projects (Cooper \& Reichelt, 2004; Baguma \& Ssewanyana, 2008). The domain of BPC still suffers from a lack of consistent theoretical foundations (e.g., Guha, Grover, Kettinger, \& Teng, 1997; Huizing, Koster, \& Bouman, 1997; Kettinger \& Grover, 1995; Teng, Fiedler, \& Grover, 1998). In particular, we argue that a plethora of research foci and diverse units of analysis limit the growth of the body of knowledge on BPC.

Lecturers and professionals also struggle with existing BPC training approaches that are frequently based on intuition rather than empirical data (Caulfield \& Maj, 2002; Gardiner \& Ford, 1980). Traditional education approaches are often not tailored to capture the many complexities of BPC projects. While analyzing a decision, students or managers scan their memory for similar situations, using their cognition to capture current reality and mentally predicting the future state according to available alternatives (Doyle \& Ford, 1998; Wang \& Chen, 2012). Thus, experience with BPC projects 
presents the only scarce resource to convey knowledge about BPC (Jurisch, Cuno, Palka, Wolf, \& Krcmar, 2012).

One way to systematically create experiential learning environments that are grounded in empirical data is through system dynamics (SD) modeling and simulation (Forrester, 1994; Spector \& Davidsen, 1997, Spector, 2000). Researchers and practitioners use SD in a variety of use cases that show that SD is suitable to describe, model, and convey structure and dynamics of complex systems through modeling feedback loops, delays, and uncertainties (Forrester, 1961, 1985, 1992; Senge, 1990; Spector \& Davidsen, 1997). Training approaches based on SD lead to high participant awareness and encourage exploration through the ability to modify and replay the models (Madachy, 2008). For instance, experimenting with dynamic graphs enables training participants to understand important effects, relationships, and complex feedback loops in BPC projects more effectively as is the case with traditional lecture formats (Yamamoto, 2010; Vergidis, Tiwari, \& Majeed, 2006; Xirogiannis \& Glykas, 2004).

The goal of this research is to explore the usefulness of SD for consolidating the findings from case studies and conveying the structure and dynamics of BPC projects. By eliciting impact factors and their mutual relationships from BPC projects, we aim to increase transparency of causal links and effects within these projects, thereby enhancing practitioners' abilities to anticipate and cope with these phenomena. This leads us to the following research questions:

- Which impact factors and relationships have to be considered for a SD simulation model for BPC projects?

- What are the benefits and limitations of SD for BPC learning offerings?

In order to demonstrate the use of SD for simulating certain developments in BPC projects, we develop a SD simulation model for managing and understanding employee morale when changing a business process. The proposed SD simulation model focuses on employee morale, since several researchers consider "employee morale" a pivotal variable determining the success of BPC projects (Grover, 1999; McAdam \& Donaghy, 1999). Simultaneously, research also asserts that employee morale is affected by many relationships, which might have non-linear characteristics that make it particularly difficult to manage and forecast. In general, we follow the guidance of Baguma and Ssewanyana (2008) when developing our SD simulation model. As SD models are limited by the extent of available empirical data, we thus extend the guidelines for SD by grounding our simulation model in case studies of BPC projects published in research literature. In doing so, we explore a novel source of empirical data required for SD simulation models (Morecraft, 1982).

We contribute to the domain of BPC by making the abundance of case studies on BPC projects available to SD modeling. In doing so, we present SD models as a novel approach to review and consolidate the complex and often non-linear findings from BPC case studies. This paper also contributes to the domain of knowledge management and learning by suggesting SD as a valuable approach to illustrate, explain, and convey the complex relationships between important variables in BPC projects. We hope to inspire researchers and practitioners to use SD as an effective instrument that makes the complex nature of BPC projects available to discourse among researchers, lecturers, students, and BPC professionals.

The remainder of the paper is organized as follows. In section 2, we review the literature on BPC and system dynamics. In section 3, we outline our research design and 
explain the problem statement, data collection, and causal loop modeling. In section 4, we detail our SD simulation model and demonstrate the use of it for managing employee morale in BPC projects. We discuss our results and limitations in section 5 and conclude the paper with an outlook on future research opportunities in section 6 .

\section{Literature review}

\subsection{Business process change}

$\mathrm{BPC}$ has its roots in Business Process Reengineering (BPR) and Total Quality Management (TQM). Hammer and Champy (1993) define BPR as the fundamental rethinking and radical redesign of business processes to achieve dramatic improvements in critical contemporary measures such as cost, quality, service and speed. BPR, business process innovation (BPI) or business process transformation (BPT) are frequently used synonymously for the same phenomenon. According to Grover and Markus (2008) these variations in name of essentially the same concept were part of a bandwagon effect. All BPR, BPI and BPT projects are radical, revolutionary, and one-time undertakings (Davenport, 1993; Hammer, 1990; Grover \& Markus, 2008), TQM is considered to be an integrated and more evolutionary approach for process improvement (Bucher \& Winter, 2007). Furthermore, TQM aims at improving quality of products and services in all departments and functions (Koch, 2011). While both approaches BPR and TQM share the common goal of improving processes, they are also frequently used complementary (Grover \& Markus, 2008).

Against this background, BPC can be viewed as a management concept that involves any type of process change - revolutionary (radical) or evolutionary (continuous) (Grover, Kettinger, \& Teng, 2000; Grover \& Markus, 2008). Fig. 1 illustrates the central elements of BPC.

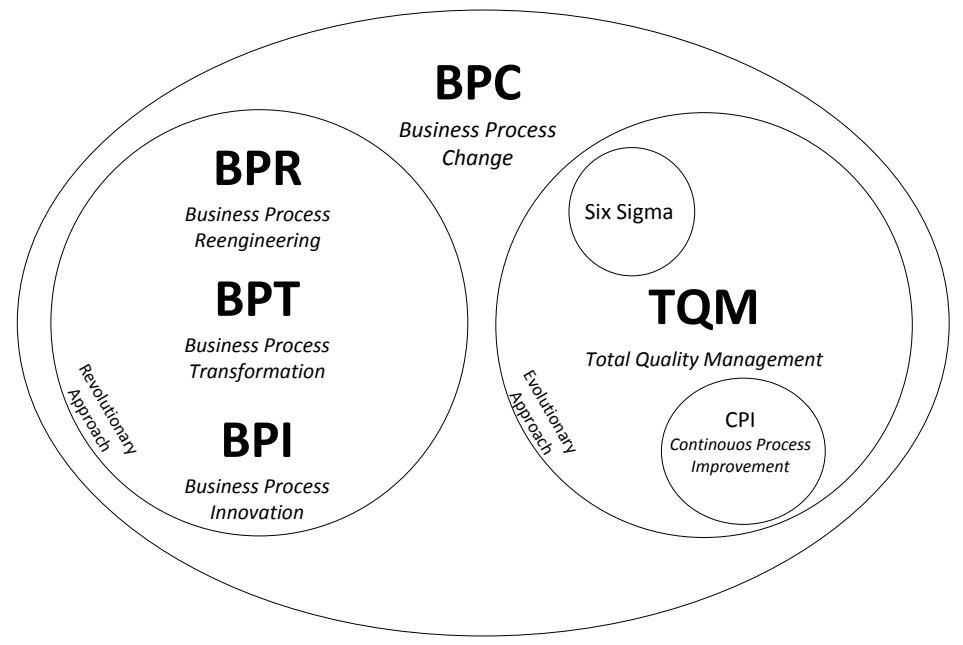

Fig. 1. Central elements of business process change 


\subsection{Business process change success factors}

Over the last two decades, the success of BPC has been studied through several theoretical and practical lenses. Two dominant streams of research can be identified. The first group of researchers (e.g., Grover, 1999; Guha, Grover, Kettinger, \& Teng, 1997; Kettinger \& Grover, 1995) address the topic of BPC primarily from an organizational change perspective, while more recently a second group of researchers (e.g., Grover, Teng, Segars, \& Fiedler, 1998; Melville, Kraemer, \& Gurbaxani, 2004; Radhakrishnan, $\mathrm{Zu}, \&$ Grover, 2008) analyse the impact of IT investments on organizational performance from a process-oriented perspective.

The most prominent models analysing the critical success factors for BPC (i.e., Grover, 1999; Guha, Grover, Kettinger, \& Teng, 1997; Kettinger \& Grover, 1995) share the same assumption, namely, that successful BPC is strategy-driven. In this respect, BPC is always a strategic change (Guha, Grover, Kettinger, \& Teng, 1997). Top management holds a key role in supporting the respective strategic change initiative while also encouraging a change-ready organizational culture (Kettinger \& Grover, 1995; Skerlavaj, Stemberger, Skrinjar, \& Dimovski, 2007). Often this is referred to as establishing an innovative organizational environment, which assumes a central role in most BPC models (Guha, Grover, Kettinger, \& Teng, 1997; Kettinger \& Grover, 1995).

The success of BPC also depends on the quality of the implementation process (Trkman, 2010). Therefore, BPC needs to be accompanied by change management to ensure joint efforts between managers and employees. Grover (1999) argues that a lack of change management inhibits the success of BPC projects with respect to processes and people factors. Bearing this in mind, it is no surprise that all BPC models (e.g., Grover, 1999; Guha, Grover, Kettinger, \& Teng, 1997; Huizing, Koster, \& Bouman, 1997; Kettinger \& Grover, 1995) propose an alignment of process and change management practices, along with the change environment, in order to improve business processes and obtain measurable and sustainable competitive performance gains.

Huizing, Koster, and Bouman (1997) add an interesting perspective to common BPC research models: the concept of fit and organizational performance in change projects. Their framework distinguishes five dimensions: level of ambition, breadth, depth, planning, and coordination of the change process. Based on thorough empirical verification of their research framework with 90 organizations Huizing, Koster, and Bouman (1997) conclude that the ambition for change has to be balanced with the organization's ability to change. They further identify that "the higher the level of ambition, the larger the number of critical activities [...] that need to be tackled and the more organizational aspects that have to be changed [...]" (Huizing, Koster, \& Bouman, 1997, p.112). Even though theoretical and practical evidence highlights the importance of the dimension level of ambition or project scope, none of the prominent BPC models (i.e., Guha, Grover, Kettinger, \& Teng, 1997; Kettinger \& Grover, 1995) incorporate it as a critical success factor for BPC.

The employment of the IT dimension and its relation to BPC success has produced contradicting results. While some researchers argue that IT poses an important catalyst and enabler for BPC (Trkman, 2010), others argue that IT may not necessarily be a critical success factor for BPC (Grover, 1999; Guha, Grover, Kettinger, \& Teng, 1997; Kettinger \& Grover, 1995). Besides the ongoing debate on the business value of IT, the effect of IT on business performance has in fact often been contested (Karimi, Somers, \& Bhattacherjee, 2007; Radhakrishnan, Zu, \& Grover, 2008). For instance, the relationship between IT investment and firm performance through an input-output perspective is well 
described in production function and process-oriented models (Melville, Kraemer, \& Gurbaxani, 2004). Particularly, process-oriented models offer helpful insights on how IT can provide business value through the use of business processes. Soh and Markus (1995) introduced a conceptual framework which posits that IT investments lead to IT assets (IT conversion process), IT assets to IT impacts (IT use process), and IT impacts to organizational performance (competitive process). Melville and colleagues (2004) also introduce a process-level model, which depicts that IT resources and complementary organizational resources have to be combined into a business process which than yields business process performance. Recently, Trkman (2010) has argued that the value of IT for successful BPC should also be measured at process level, since the prime effects of IT are in fact expected to be realized at process level (Melville, Kraemer, \& Gurbaxani, 2004).

The short summary of existent research on the topic of BPC success shows that their research outcomes produced to some extent conflicting results and few reliable generalizations. Till today, none of the proposed success factor models for BPC (e.g., Guha, Grover, Kettinger, \& Teng, 1997; Huizing, Koster, \& Bouman, 1997; Kettinger \& Grover, 1995; Teng, Fiedler, \& Grover, 1998) managed to prevail. Grover and Markus (2008) stated that the field of BPC still suffers from a lack of knowledge on adequate theories and methods. This lack of knowledge is also evident in prominent BPC models and leads to the following shortcomings. First, the majority of research models for BPC success are rather atheoretical (i.e., Karimi, Somers, \& Bhattacherjee, 2007; Kettinger \& Grover, 1995; Teng, Fiedler, \& Grover, 1998). Most of them fail to evaluate the identified BPC success factors from different theoretical angles. Second, another group of researchers makes theoretical assumptions on only specific causal relations, e.g., impact of IT or change management on BPC success (i.e., Grover, Teng, Segars, \& Fiedler, 1998; Huizing, Koster, \& Bouman, 1997), which sometimes stand isolated in the overall context of BPC success. Third, some research models on the topic of BPC success stem from only one or few case studies in domain specific settings (i.e., Caron, Stoddard, \& Jarvenpaa, 1994; Larsen \& Myers, 1997), thus limiting the generalizability power of these research results. More so, the level of granularity in which the various BPC success factors and their relations are presented renders it difficult to derive a detailed causal loop or SD simulation model for BPC success.

\subsection{System dynamics for business process change}

To minimize the impact of BPC failures and to address these complexities, simulation has been proposed as one of the techniques suitable for the support of BPC (e.g., Spector \& Davidsen, 1997; Kettinger, Teng, \& Guha, 1997; Hlupic, de Vreede, \& Orsoni, 2006; Jahangirian, Eldabi, Naseer, Stergioulas, \& Young, 2010). Shannon (1975) defined simulation as the process of designing a model of a real system and conducting experiments with this model for the purpose, either of understanding the behavior of the system or evaluating various strategies. One popular simulation technique is system dynamics (Greasley, 2009).

SD is a methodology used for the analysis of the behavior of complex systems. $\mathrm{SD}$ is a rigorous approach in capturing interrelationships among variables and in handling dynamic aspects of the system behavior (Sterman, 2000). SD attempts to understand why things happen by identifying the structure behind the behavior, using the idea of system archetypes to describe recurring structures in systems (Greasley, 2009). SD is strongly related to systems thinking (Senge, 1990), which states that structure determines behavior. So changing the business system's structure means changing the behavior of the system 
and thus changing the future of a company (Ashayeri, Keij, \& Broecker, 1998). SD is divided into two stages, qualitative and quantitative analysis. In the first stage, modelers identify system variables for the problem in concern and develop a qualitative system model in the form of a causal loop diagram (CLD). In the second stage, the qualitative model is transformed into a system flow diagram and is calibrated for quantitative analysis using computer simulation (Quaddus \& Intrapairot, 2001). The results of such simulations can help organizations in forecasting, solving problems and developing policies (Baguma \& Ssewanyana, 2008). Over the years, SD has been applied to many areas such as supply chain management (e.g., Anderson, Morrice, \& Lundeen, 2003; Spengler \& Schroeter, 2003; Akkermans \& Dellaert, 2005), project management (e.g., Park \& Pena-Mora, 2003; Lyneis, Cooper, \& Els, 2001; Taylor \& Ford, 2006), change management (e.g., Eden, Williams, \& Ackermann, 1998; Howick \& Eden, 2001; Cooper \& Reichelt, 2004), and BPC (e.g., van Ackere, Larsen, \& Morecroft, 1993; Ashayeri, Keij, \& Broecker, 1998; Burges, 1998; Baguma \& Ssewanyana, 2008). Surveying all of these works is beyond the scope of this article. Thus, we focus here on articles dealing with BPC.

One of the early applications of SD in BPC was by van Ackere, Larsen, and Morecroft (1993). The authors explore the link between SD simulation and business process redesign. For their analysis they selected a classic well-known logistical system a multi-stage production and distribution system - also known as the 'beer game'. The model of the beer game shows the major processes graphically and how they are linked within an organization. With their work they illustrate changing concepts and tools in action. Ashayeri and colleagues (1998) applied the SD simulation approach to develop a conceptual framework for conducting global BPC, i.e. restructuring processes in all functions considering customer value. They established a clear link between criteria that are important to customers (external criteria) and performance measures for internal usage (internal criteria), in order to quantify the customers' requirements and preferences. Their framework combines concepts of SD and analytical hierarchy process (ANP). With the help of ANP managers can structure the problems in a top-down way and break them down in elementary sub-problems. With the help of the SD simulation model, they can simulate which business system components will result in the highest improvement and help a company to change toward its vision. Other related applications include the work of Burges (1998) who proposes a generic SD simulation model of an organization undergoing a BPC project, which is rooted in the operations management literature. The model depicts both organization and BPC as a single process. With his modeling perspective he is focusing on competitive capabilities such as quality, cost, time and flexibility. However, the main focus is on benefits derived from cost reduction. Baguma and Ssewanyana (2008) use SD simulation model for investigating the impact of IT infrastructure on BPC. Their simulation model is based on data collected from five commercial banks. With the help of the SD simulation model they test different hypothesis and found that the role of network infrastructure is critical for improving business processes and enhancing customer services.

\subsection{System dynamics in management training and education}

Over the years, many SD simulation models have been converted into business game simulations for the use in management training and education. For example, Graham and colleagues (1992) suggest a combination of SD simulation models with conventional case studies to create learning environments for management education. They argue that model-supported case studies bring improvement in strategic thinking skills. They 
present two examples to show explicitly how cases and SD simulation models are combined and used in management education. With their work they focus on: (1) how to teach effectively inquiry skills, (2) how to teach conceptualization skills, and (3) how to enhance the ability to transfer insights into new situations. Sioutine and Spector (1999) present a SD simulation model for large-scale instructional development projects. With their learning environment the authors attempt to develop users' appreciation and understanding of the many dynamic factors involved in project planning and resource allocation, especially those pertaining to how project teams are optimally organized. Thus, managers and students learn the important factors for managing projects successfully. Barlas and Diker (2000) develop an interactive SD simulation model (UNIGAME) with the focus on academic aspects of university management. The model captures long-term, dynamic, strategic management problems, such as growing student and faculty ratios, poor teaching quality, and low research productivity. Students and managers can analyze and test alternative management strategies. The results of their study show that the proposed game is a useful technology to support strategic decision-making and a laboratory for theoretical research on how to best deal with strategic university management problems. Baume (2009) develops a SD simulation model as a strategic game (Go4C) for practical training with students and managers. The simulation game deals with the complex interrelationships of IT decisions and corporate strategy of a bank. Four players of one group assume the roles of chief information officer (CIO), chief financial officer (CFO), chief marketing officer (CMO), and chief operating officer (COO) and make decisions about projects and business ratios. The simulation game stresses along strategic decisions the communication between the four players of one group.

Surveying the articles, we found that literature provides a range of examples that make use of SD simulation for strategy or hypothesis testing, or for management and educational training. However, many of these models vary widely in the level of detail provided and their structure. Also, in our review, we did not identify learning tools for conducting BPC projects available that would adequately help practitioners in fully comprehending the important parameters of BPC projects that are grounded in empirical data.

\section{Research design}

Our research applies a SD approach as the framework for analysis, model building and simulation (Baguma \& Ssewanyana, 2008). This was a process that covered: problem statement, meta-case analysis, conceptual model, SD model building, and scenario planning.

\subsection{Problem statement}

To illustrate the topic of employee morale in BPC projects, we utilize a standard SAP reference business process ("sales process") (Konstantinidis, Kienegger, Flormann, Wittges, \& Krcmar, 2012). In order to reengineer the process, we first describe the process and determine its weak spots (Fig. 2). The weak spots in the process are labelled with flash sign.

The sales process consists of four sectors: sales, procurement, warehouse and shipping, and accounting. In the beginning the sales staff creates a proposal for the customer and checks if the products are available at the agreed date and records the 
desired delivery date on all subsequently produced documents. The produced documents are sent to the sales manager for an approval. After the approval the sales staff creates a customer order on the basis of the proposal. In the next step the procurement staff reviews the customer demand generated by the order. When the review was successful, procurement staff approves the demand. Subsequently, the warehouse and shipping director books the outgoing goods and the system creates the delivery automatically. Afterwards the warehouse and shipping director has to approve the delivery and print the shipping order. Based on the delivered customer order the sales staff creates a customer invoice. Then the accountant verifies the customer account and the booking, which were created during the process. If the accountant receives the check, it will be entered to balance the open items. The accountant always checks the accounting records, which are created during the process. The sales staff can monitor the state of the order any time during the document flow.

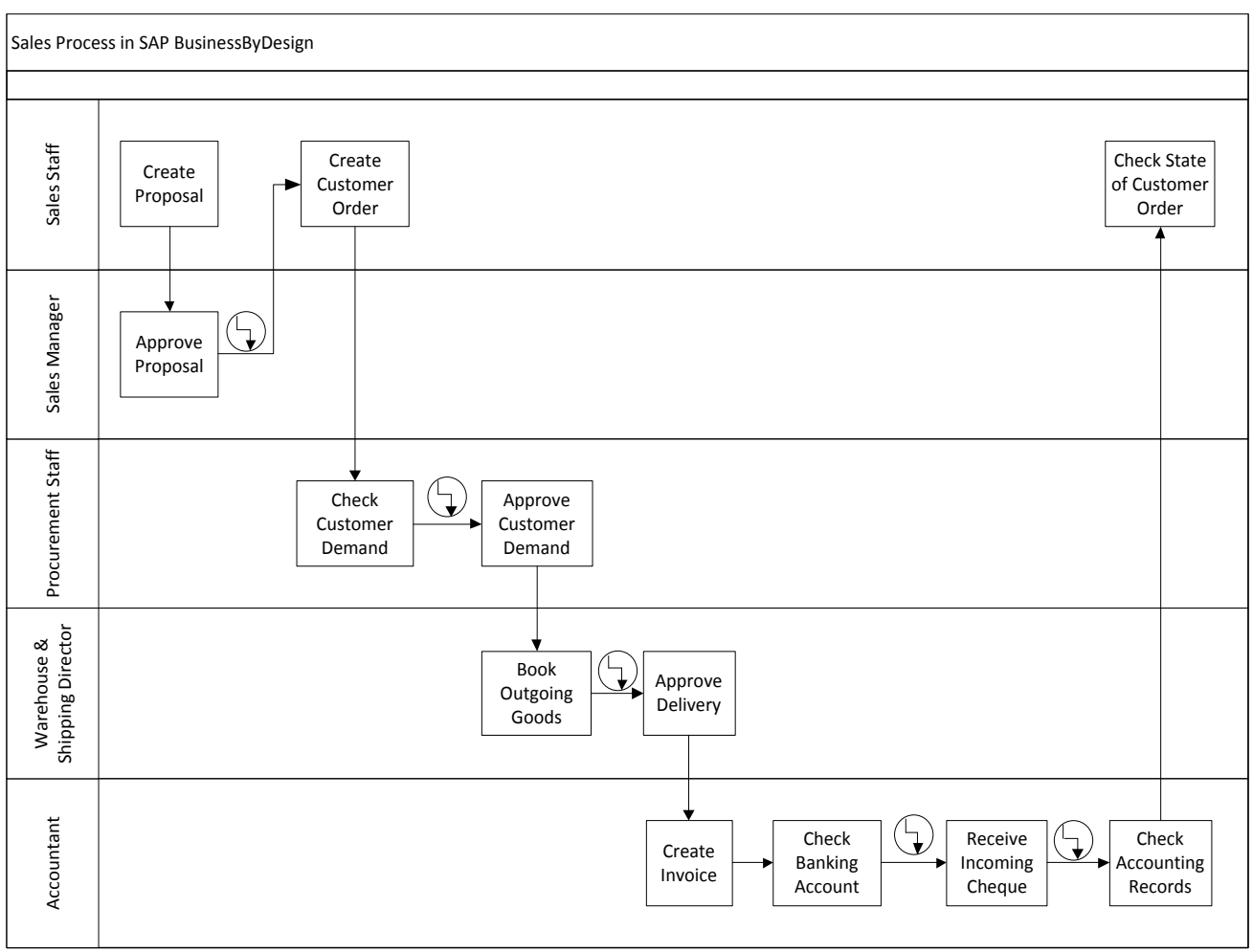

Fig. 2. Sales process

The initial situation shows that the sales process is shaped by many prove steps because of the fragmentation of the information. Such fragmentation of information involves several feedback loops in the process. However, when information is incomplete or corrupt, or when it changes, the feedback loops become very time consuming in the process. They cause higher rework, increase the work backlog, result in greater time pressure and finally negatively influence the employee morale.

Therefore, the initial situation in this reference sales process raises a fundamental question - how much emphasis should be placed on reducing these time-consuming process steps with respect to employee morale? Hence, employee morale was adopted as the dependent variable of this study. 


\subsection{Meta-case analysis}

To answer the aforementioned question, we conducted a meta-case analysis, also referred to as structured content analysis of cases (Jauch, Osborn, \& Martin, 1980) or case survey (Larsson, 1993; Lucas, 1974; Yin \& Heald, 1975). The meta-case analysis method turned out to be particularly useful for our research due to the following criteria proposed by Larsson (1993): (1) the research area comprises a huge number of case studies (i.e., cases of BPC projects) (Yin \& Heald, 1975); (2) the unit of analysis is the organization (i.e., the organization conducting the BPC project) (Jauch, Osborn, \& Martin, 1980); (3) a broad range of impact factors is of interest (Jauch, Osborn, \& Martin, 1980); and (4) it is difficult to do structured primary research across cases in this research domain.

\section{Sample collection}

For the case sample collection, we applied a detailed screening of literature. We used the key words "business process", "business process change", "business process reengineering", and "business process transformation". After the initial literature screening, we identified more than 5,000 references for each combination of key words and the term "case study". These were found through traditional channels (e.g., libraries), conference proceedings, online database services (e.g., Emerald, EBSCO, Science Direct and Google Scholar), consulting journals, and other web search tools. To determine the relevance of these articles, we further explored titles, abstracts, and keywords. After this step, the identified 5,000 references were further reduced to 217 case studies. Next, we excluded case studies with the following attributes: (1) none or very little information about the case; (2) none or very little information about the impact factors for the success of the BPC initiative; and (3) focused on the technology, not on the BPC initiative. After eliminating these case studies we reached a final sample of 65 case studies, comprising 46 journal articles, 13 book sections, 2 conference articles, 3 theses, and 1 working paper. The final sample consists of a wide set of international BPC initiatives, 43 in private and 22 in public organizations. The articles span the years 1993 to 2010 and have an average length of 14 pages.

\section{Data collection}

The coding scheme "documents and guides the conversion of qualitative case study data into quantified variables" (Larsson, 1993, p.1530) and thus stands as the core element of a meta-case analysis. We designed the coding scheme in the following manner. First, we defined the variables related to managing employee morale in BPC projects including their objects for our research. In line with Larsson (1993), our coding scheme comprises variables that represent the aspects of the study design (e.g., training rate, hiring rate, leaving rate), the publication status (e.g., ranging from journal article to book section), and control variables relevant to the studied phenomenon (e.g., the size of the BPC project).

\section{Data coding}

As a result, a master list of the variables evolved, which we employ for the frequency coding. The frequency coding of the variables and their interrelationships is based on the methodology proposed by Lacity, Khan, Yan, and Willcocks (2010). Following this methodology, we analyzed how often a variable occurred in a case study, and coded and accumulated the frequency of each variable. Afterwards, we empirically examined the relationships between the variables and assigned two possible values: ' +1 ', '- 1 '. We coded ' +1 ' for positive relationships, ' -1 ' for negative relationships. However, all relationships we coded have a positive influence on employee morale. 
To ensure consistent coding at the outset, we established inter-coder reliability. The results indicate a Krippendorf's Alpha of 0.68 , which is an acceptable inter-coder reliability (Krippendorf, 1980).

\subsection{Data analysis}

\section{Analysis of the dependent variable}

We coded the dependent variable 'employee morale' 27 times in our set of case studies. Employee morale refers to the degree to which employees feel comfortable in their current roles and responsibilities and that the workload is adequate to their skills and responsibilities. Employee morale also refers to the level of involvement of employees in decision making (Paper, 1997). Some change projects seek to empower the employees to achieve higher employee morale (Stemberger, Kovacic, \& Jaklic, 2007), others try to improve employee morale by "changing responsibilities from routine transaction processing to value-added accountability" (Ballou, 1995, p.23). High employee morale is especially important as satisfied employees are able to generate higher value (Newman, Cowling, \& Leigh, 1998).

Table 1

Frequency of impact factors on employee morale

\begin{tabular}{llc}
\hline$\#$ & Identified impact factors on employee morale & Frequency \\
\hline \hline 1. & Customer satisfaction & 58 \\
2. & Management support & 48 \\
3. & Training & 45 \\
4. & Quality of products and services & 45 \\
5. & IT resources & 42 \\
6. & Governance structure & 40 \\
7. & Measurement for controlling and monitoring business processes & 40 \\
8. & Management vision/understanding & 39 \\
9. & Change understanding & 32 \\
10. & Reduction of cycle time & 31 \\
11. & Cost reduction & 30 \\
12. & Performance measurement & 28 \\
13. & Availability of process management methods \& tools & 27 \\
14. & Management resource support & 18 \\
15. & Productivity & 18 \\
16. & IT capability & 15 \\
17. & Organizational learning capability & 11 \\
18. & BPM methods \& tools capability & 7 \\
& Total & 574 \\
\hline
\end{tabular}

\section{Analysis of impact factors on employee morale in BPC research}

Based on our set of 65 case studies, we identified 18 impact factors on employee morale used in BPC research (Table 1). We counted the frequency of the words and their synonyms. As some words may have multiple meanings, we always counted the wordfrequency in the whole sentence context. We sorted these impact factors by frequency of use. 
Analysis of relationships between employee morale and BPC variables

In this section, we summarize the findings on the 27 relationships we coded between employee morale and their impact factors (Table 2). We aggregated some of the findings into broader categories, as according to Forrester (1976) phenomena with similar structures may be aggregated together. We treated all coded relationship-frequency as significant, as also relationships coded only once may have a significant impact on employee morale.

\section{Table 2}

Relationships between impact factors and employee morale

\begin{tabular}{lc}
\hline Dependent variable & Employee morale \\
\cline { 2 - 2 } Impact factors on employee morale & Number of frequency \\
\hline \hline Productivity & 3 \\
Management vision/understanding & 2 \\
Customer satisfaction & 2 \\
Training & 1 \\
Reduction of cycle time & 1 \\
Cost reduction & 1 \\
Quality of products and services & 1 \\
Governance structure & 1 \\
Resources & \\
IT resources & 3 \\
Process management methods \& tools & 1 \\
Performance measurement & \\
Measurement for controlling and monitoring business & 3 \\
processes & 1 \\
Performance measurement & \\
Management support & 1 \\
Management support & \\
Management resource support & 1 \\
Skills and capabilities & 1 \\
BPM methods \& tools capability & \\
IT capability & 27 \\
Change understanding & 1 \\
Organizational learning & \\
Total & 2 \\
\hline
\end{tabular}

The coding results show that employee morale is not straightforward to analyze. Not only impact factors influencing employee morale must be taken into consideration 
but also the interaction between these impact factors. These relationships are outlined in the conceptual model (Fig. 3)

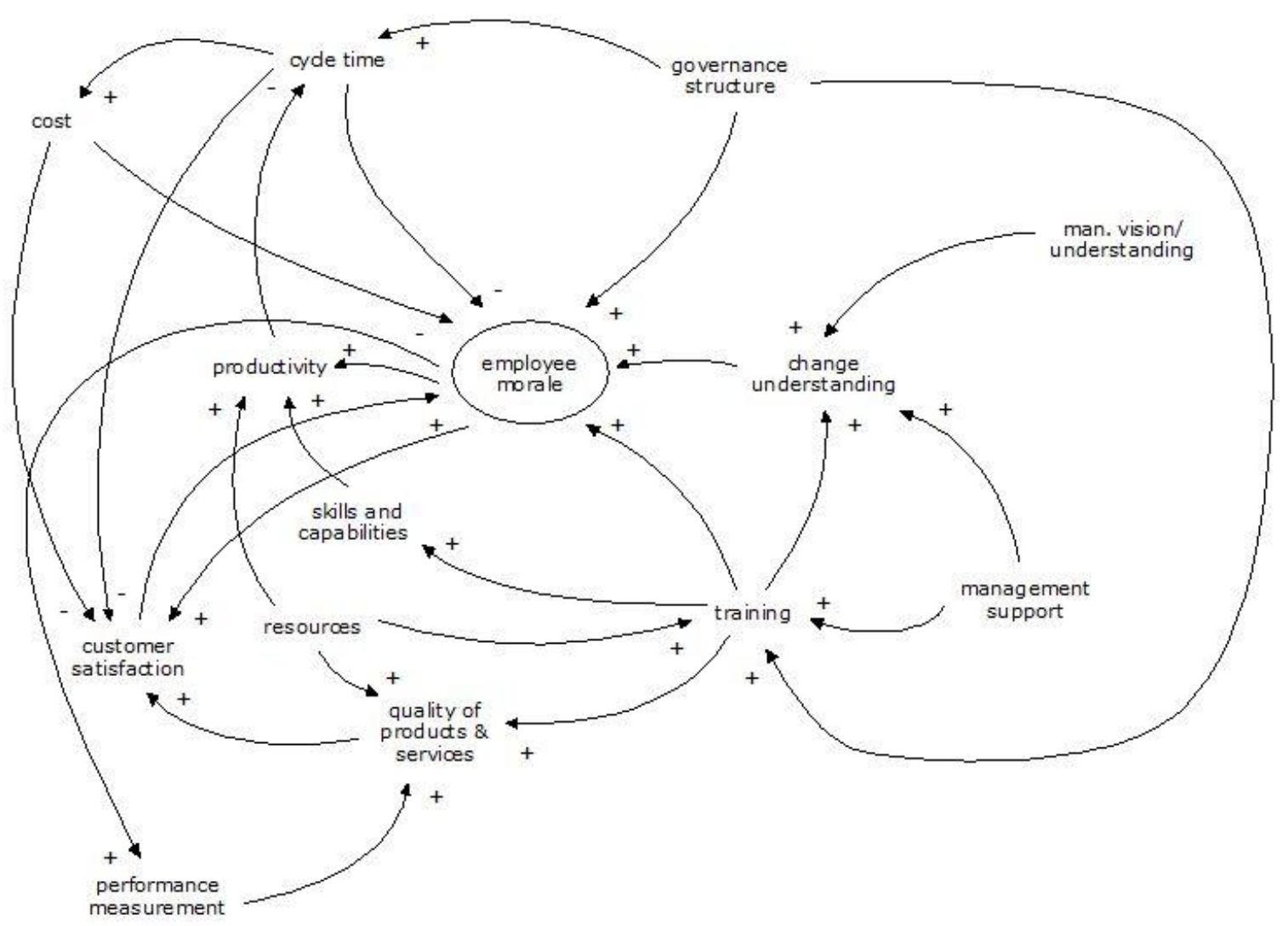

Fig. 3. Causal loop model of relationships between impact factors and employee morale

Conceptual model

During this process step, a conceptual model of the problem, known as a causal loop diagram (CLD) was created (Fig. 3). The CLD model is based on the previous step 'data coding' and captures the interactions and relationships between the identified variables. CLD is a representation that consists of variables connected by arrows denoting the causal-and-effect relationships among the variables (Madachy, 2008). Causal relationships support the clarification of the actual structure of the examined problem, as the clear picture of the problem's structure improves understanding of the observed phenomena (Forrester \& Senge, 1980). Moreover, Schwaninger and Hamann (2005) state that propositions regarding causal relationships need to be carefully examined by drawing on additional theoretical or empirical data. Causally related variables indicate how the dependent variable behaves when the independent variable changes (Sterman, 2000). In CLD this behavior is represented with the help of positive or negative signs. For more detail on CLD, we refer to Sterman (2000).

The first factor in Fig. 3 that influences employee morale represents the factor management vision or understanding, which is represented through an indirect link from the factor change understanding. As Stemberger, Kovacic, and Jaklic (2007) found, a 
clear management vision enables employees to better understand the project goals or project changes, which in turn has a positive effect on employee morale and commitment (Harvey, 1994). Hammer \& Champy (1993) noticed that management support also positively influences employee change understanding and consequently positively influences employee morale. The factor change understanding is furthermore affected by training, i.e. training represents one method to prepare employees for the change.

Training represents another important factor influencing employee morale, especially when employees gain new skills for the changed processes and tasks (Newman, Cowling, \& Leigh, 1998). Furthermore, successful training enhances employees' skills and capabilities, i.e. skilled employees are capable to support and transform the organizational vision (Albizu, Olazaran, \& Simon, 2004). Training has also an essential positive impact on the quality of the products and services (Newman, Cowling, \& Leigh, 1998). The results of higher quality are satisfied customers (Thong, Yap, \& Seah, 2000), i.e. the enhancement of the quality also positively influences employee morale, in the model represented by an indirect link from customer satisfaction. The factor resources presents one of the most significant factors that impact quality (Harvey, 1994; Geier, 1997; Newman, Cowling, \& Leigh, 1998). Along with resources and training, performance measurement positively influences the quality of products and services (Dignan, 1995; Jackson, 1995), and has an indirect positive effect on customer satisfaction and employee morale. In turn, positive employee morale causes that performance measurement is performed more efficiently (Harvey, 1994).

Productivity is another important factor in this model. This factor is strongly affected by employee morale. Especially, committed and motivated employees have a significant impact on productivity (Proctor \& Gray, 2006). Other factors influencing productivity are skills and capabilities, and resources. In turn, productivity influences the cycle times, i.e. when productivity is low it results in higher cycle times and vice versa. Such effects are illustrated by a minus sign in the model. Subsequently, cycle time influences employee morale, e.g. if cycle times are reduced then employee morale increases. Similarly to cycle times, the reduction of cost plays an important role by influencing employee morale and customer satisfaction (Weise, 1996), i.e. if employees drive the costs down, e.g., through reduction of cycle times, then employee morale and customer satisfaction increase.

The factor governance structure positively impacts employee morale. It implies that a formalized governance structure is used for the project as opposed to the existing structure of the organization (Huizing, Koster, \& Bouman, 1997). Working in a team results in higher employee morale (Harvey, 1994).

\section{System dynamics simulation results}

\subsection{System dynamics model}

SD modeling refers to a mathematically formalized version of a theory. The proposed SD model is based on the conceptual model, i.e. on the CLD, elaborated in the previous step. The proposed SD model focuses on capturing the physical flows and decision-making processes carried out by the business game players. The physical flows represent stocks, which are natural accumulations with physical meaning, and are invariably specified by quantitative measures. An example of the physical flow in a model of a human resource department includes a certain average lag in headcount required to accomplish the projects tasks. On the other hand, the decision-making rules include procedures for determining hiring or downsizing goals, or changes in price. Physical flows are relatively 
easy to capture, whereas to model the decision making processes of the participants is considerably harder (Sterman, 1987). Therefore, we use heuristics while modeling such decision-making rules, as proposed by Sterman (1987).

The whole SD model as depicted in Fig. 4 describes the dynamics of employee morale. It is based on the identified variables and their interactions as introduced above. The SD simulation is carried out with the Powersim software in version 8 , which is capable of modeling system dynamics. We use several arrays to replicate the model structure without having to duplicate the model, in order to implement all four sectors from the sales process. The model data are based on several assumptions: (1) the new hired employees are only half as productive as experienced employees and (2) graduate into experienced employees only through training; (3) each month $5 \%$ of employees leave the project; (4) employee morale is set to $72 \%$ and customer satisfaction is set to $85 \%$ at the beginning of the BPC projects; (5) for other variables such as the number of experienced employees, or costs for employees and other resources we use sample values that can be modified by the user in the management dashboard at the beginning of the SD simulation. The management dashboard is designed as the user interface to the SD simulation for access to model parameters and model settings without modifying the actual model's equations. The effect factors between data interaction, i.e. the behavioral repercussions of a change in one variable to another, are gathered from the 'CIO business game' (Baume, 2009), which relies on real empirical project data.

The core variable 'emp_morale', represented as a stock in the model, changes its current value by adding the value of inflows and subtracting the value of outflows. The inflow 'emp_morale_rate in_delta' accumulates the effect of the variables: 'time_spent_in_training', 'customer_satisfaction', 'BPC_cycle_time', 'cost total', and 'governance_structure'. Any change in these variables produces an increase or decay in 'emp morale' by a fraction of 0.005 . The variable 'time spent in training' increases 'emp_morale' when the time spent in training is above $10 \%$ otherwise 'emp morale' is decreased. If 'customer_satisfaction' drops below $80 \%$ then 'emp_morale' drops as well. Increase in 'BPC_cycle_time' causes a decrease in 'emp_morale'. The variable 'BPC_cycle_time' is dependent on productivity, which utilizes the effect of error generation and the number of employees available for the BPC project. Adding the feedback from 'cost total' to 'emp morale' captures the costs for employees and other resources. If the costs exceed the current earnings, 'emp morale' will decay. The variable 'governance_structure' utilizes the variable 'man_emp' that represents the number of managerial personnel needed for BPC projects to supervise effectively. A gap in the managerial personnel drops the employee morale. The second inflow rate 'emp_morale_rate_in' captures the effect of change understanding. The variable 'change_understanding' captures the impact of change in amount of employees by multiplying the number of experienced employees by employee morale and the number of new employees by their start morale value. The outflow rate 'emp_morale_rate_out' is used to reach equilibrium in the dependent variable, i.e. the outflow rate uses 'emp_morale' as input variable.

The variable 'error_generation' is dependent on the amount of time spent in training and on employee morale. It ascends or descends by a fraction of 0.04 multiplied by the time spent in training and subtracted from a common error generation, in this case by 0.2 , when time spent in training remains zero. The second variable employee morale uses the same fraction rate and increases error generation when it drops under $70 \%$. The effect of error generation on quality is simply its reverse function, which is implemented as 1-error_generation. Quality and employee morale effects customer satisfaction by using the same fraction rate, i.e. 0.04 . 


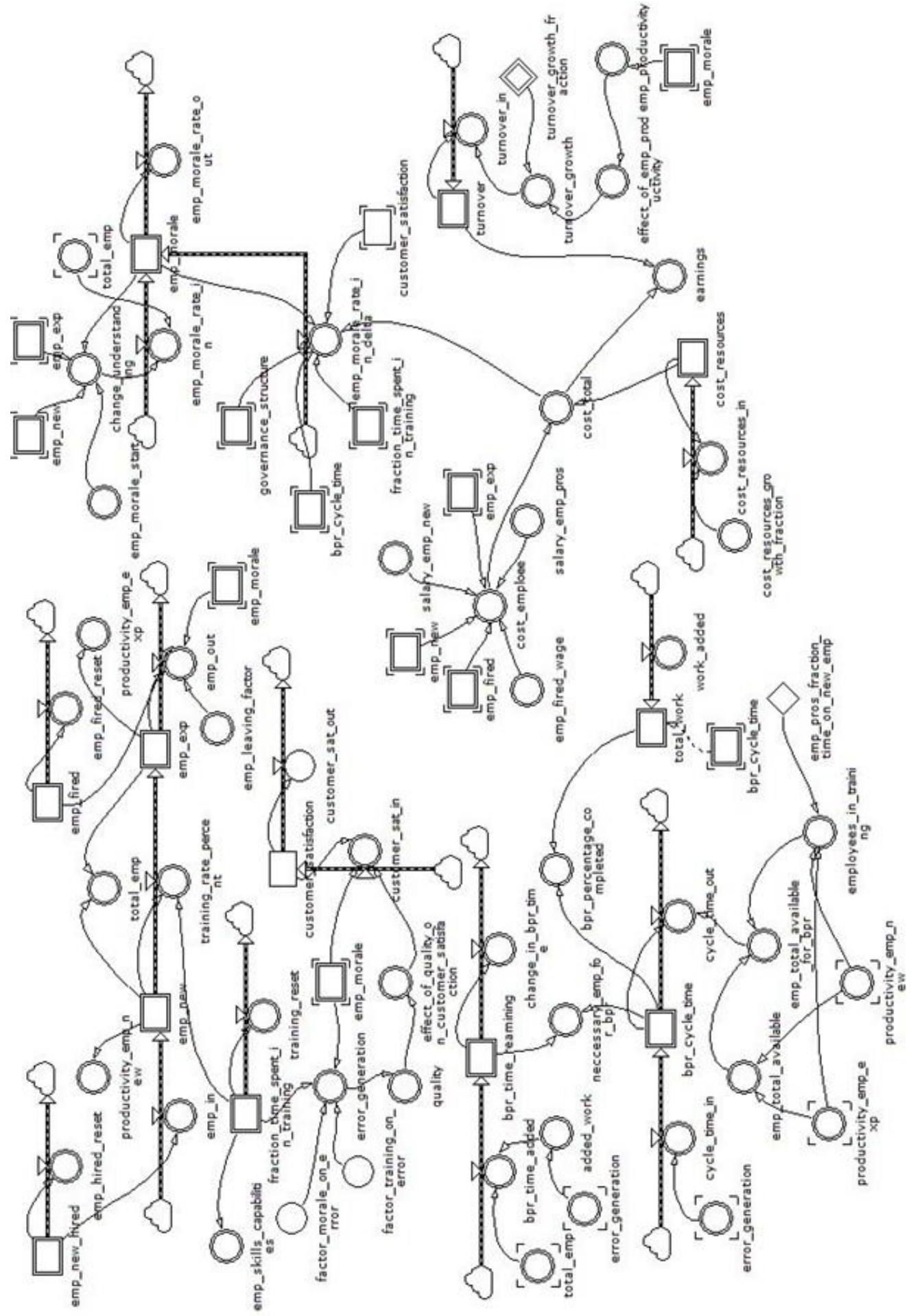

Fig. 4. System dynamics simulation model 


\subsection{Scenario planning}

For the scenario planning, we formulate two heuristics for the case "managing employee morale in BPC projects", as with the help of heuristics it is easier to understand the decision making processes of the participants (Sterman, 1987):

1. The first heuristic refers to the comparison of the average skill level of the employee with the desired average skill level needed for the project. If employees perceive their assignments as too easy and tiresome, their overall morale will decrease. At the same time, if the task is too challenging, the employees may become frustrated, and the morale will drop as well. This might also impact overall team morale. Thus, the goal is to adjust the actual skill level of the employee towards the target skill level needed for the BPC project.

2. The second heuristic refers to the reduction of cycle times. It involves the reallocation of decision-making and responsibility downwards the organizational hierarchy, granting employees the ability to affect process outcomes. Giving employees the chance to act on their own might result in several positive implications in the process outcome, such as increased efficiency in employees because of increased ownership in their work, increased productivity, reduced costs, job satisfaction and increased employee morale. Thus, the goal is to provide a positive management support (e.g., trust, authenticity) regarding responsibility for own output.

\subsection{Scenario 1. Reduce rework cycles by accelerating the training for new employees}

For the SD simulation experiments, we took a base case scenario from SAP for the sales process. It shows that there is a total rework of 384 tasks or $1.92(384 / 200)$ tasks per employee and $72 \%$ employee morale. Furthermore, at the beginning new employees are only half as productive as experienced employees, and new hired employees are more likely to generate errors, as they do not have the desired skill levels. Therefore, too many new employees on a task decrease the overall employee productivity by introducing errors in their tasks, which must be reworked at a later date. However, expecting less error generation and decrease in amount of rework cycles without providing corresponding training would be unfeasible. Newly hired employees transform into experienced employees only through training overhead. Thus, the question that arises in this scenario is how a unit increase (e.g., an increase of 5\%) in skill level of employees would change the rework and morale pattern. In the first SD simulation scenario, we therefore analyze the impact of accelerating the training for newly hired employees in order to reduce the rework cycles arising from error generation due to the lack of desired skill levels.

By simulating scenario 1 , the results show that if we consider accelerating the overall training of new employees, e.g., a stepwise increase from 5\% to $35 \%$ per month, then the new employees graduate faster into experienced employees. Moreover, the overall error generation rate is decreased from 0.098 to 0.065, i.e. an improvement of approx. $32.3 \%$. As error generation is compounded with rework cycles, we observe that when error generation is below $7 \%$, then the rework cycles are reduced by $28 \%$, i.e. a total rework of 556.5 tasks (2.9 tasks per employee) and the employee morale is increased from $68 \%$ to $93 \%$, i.e. an increase of $37 \%$ (Fig. 5). Compared to the base scenario this is a significant improvement. 


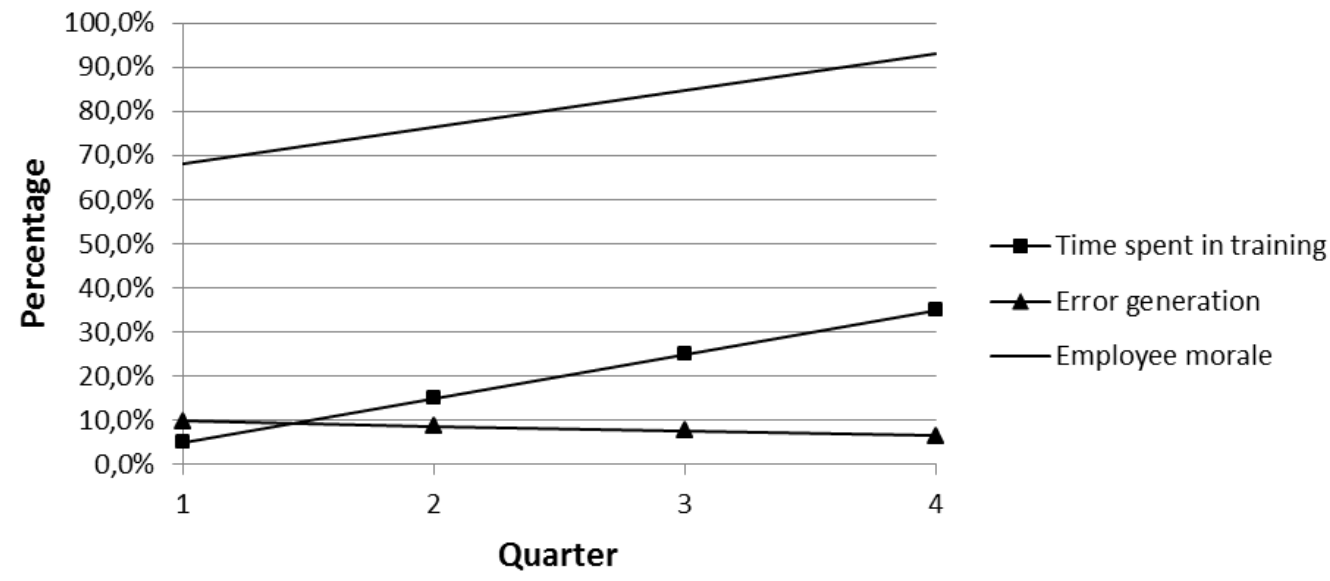

Fig. 5. SD simulation results from scenario 1

However, if we increase the time spent in the training above $60 \%$, this produces a lag in the desired workforce, i.e. the employees are not able to accomplish the work. This results in employee tediousness and influences negatively the employee's morale. As the SD simulation results show an increase in training above $60 \%$ leads to a total rework of 442 tasks (2.21 tasks per employee) and a $23 \%$ decrease in employee morale. In addition, if employee moral falls below $65 \%$, the attrition rate is increasing. In comparison to the base scenario there is an overall deterioration.

Based on the SD simulation results, we can conclude that training overhead between $30 \%-60 \%$ has a positive impact on employee morale and on overall productivity. Both factors lead to a positive change in the rework pattern. We can also add that if the time spent on trainings falls below $30 \%$ then the overall employee morale is decreasing, as employees feel most likely disappointed that their company is not investing in them. Furthermore, if the time spent on trainings exceeds $60 \%$, employee morale is decreasing as well, since the extensive trainings reduce the time available to complete actual work, i.e. too many employees must interrupt their daily tasks and assist in the training process of new employees. This causes increased cycle times, delays on time deliveries and increases the time pressure on employees.

\subsection{Scenario 2. Shorten the approval process}

In the current sales process, many process steps are filled with checking and controlling activities. For example, the sales staff always needs to send the created proposal to the sales manager for approval. Establishing such non-value added controls and approval activities along a process increases process duration and cost. Employees who perform the process steps are not permitted to make decisions on their own. Instead, they need to consult a superior in order to obtain approval. However, if the organization or a manager holds a positive attitude toward employees' reliability and goodwill in a different decision situation, employees' performance and morale is positively influenced (Lämsä \& Pucetaite, 2006). Nonetheless, some employees feel overwhelmed, if they need to take the responsibility for the decisions by themselves - especially, when the decision is compounded by a certain amount of money. With respect to this issue, we decided to add a certain threshold unit and leave the decision to the sales staff only if the value of the 
proposal is below this threshold unit. Thus, the question that arises in this scenario is how a shortening of the approval process would change the rework and morale pattern (Fig. 6).

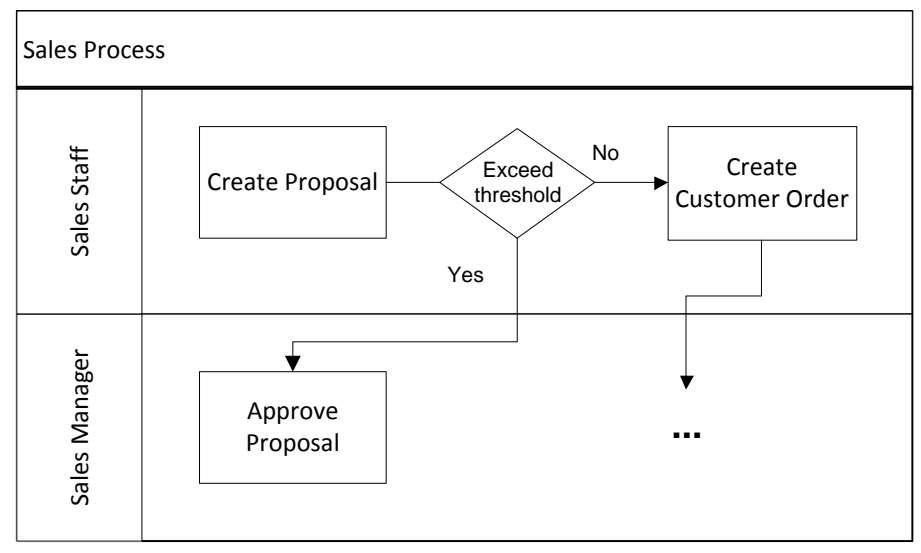

Fig. 6. Scenario 2: Shortening the approval process

Therefore, in the second scenario, we analyze the impact of removing the approval activity by the sales manager, if the value of the proposal does not exceed the approval limit. In other words, when the value of the proposal remains below the defined threshold, the employee who is assigned to perform the process step is also authorized to make the decision. After changing, the approval activity is partly removed from the sales process.

As the SD simulation results show, the process benefits from several improvements, such as fewer delays, lower overhead costs, and increased employee morale that in turn positively influences the empowerment for the task. Table 3 summarizes the SD simulation results.

Table 3

SD simulation results from scenario 2

\begin{tabular}{|c|c|c|}
\hline Policy parameter & Base scenario & $\begin{array}{l}\text { Shortening the approval } \\
\text { process }\end{array}$ \\
\hline Work completion & $\begin{array}{l}1,300 \text { tasks } \\
\text { (6.5 tasks/employee) }\end{array}$ & $\begin{array}{l}\text { 1,573 tasks } \\
\text { (7.87 tasks/employee) }\end{array}$ \\
\hline Process duration & 7 months & 5.5 months \\
\hline Number of employees & 200 employee & 200 employee \\
\hline Training overhead & $5 \%$ & $5 \%$ \\
\hline Employee morale & $68 \%$ & $82 \%$ \\
\hline
\end{tabular}

We can conclude that the partial elimination of the approval activity by the sales manager decreases the process duration by 1.5 month (approx. $21 \%$ improvement). This results in an increase in employee morale to $82 \%$. Compared to the base scenario, we can 
summarize that partly removing this controlling activity leads to an overall improvement of approx. $20 \%$ in employee morale.

\section{Discussion}

Pertaining to the research questions we set out with, we propose the following findings.

(1) Which impact factors and relationships have to be considered for a SD simulation model for BPC projects?

Employing the concept of a SD approach for developing a simulation model put forth by Baguma and Ssewanyana (2008), we coded 65 case studies departing from the central (dependent) variable employee morale. We identified 18 relevant factors impacting our dependent variable in a direct or indirect manner. 27 relationships among these factors or between factors and the dependent variable were elicited through the coding process. We found the factors of productivity, IT resources, and measurement for controlling and monitoring business processes to have the largest impact on employee morale. Employee morale in turn positively influences performance measurement, productivity and, maybe most importantly, customer satisfaction. We identified several feedback loops. The resulting SD simulation model represents a playing field for devising concrete guidance for practitioners within BPC project environments. In order to exemplify this process, we devised two heuristics and presented quantitative analyses for the resulting scenarios, demonstrating the concrete applicability of the identified impact factors and relationships to the goal of actively shaping a BPC project environment.

(2) What are the benefits and limitations of SD for BPC learning offerings?

We have shown that SD is capable of creating easily graspable and remarkably detailed models of influence factors and interactions within BPC projects. Employing SD for deriving learning environments allows researchers and practitioners to foot their analyses on vast amounts of real-world data. This also allows for the quantification of implicit and tacit impacts and relationships. The resulting model consists of clearly defined elements, including dependent and independent variables as well as directed and weighted relationships among these variables. Especially when visualized by means of a causal loop model, this makes for a strikingly intuitive and comprehensible representation of BPC project environments. If the learning process is supported by software capable of simulating these models, studying the relationships between factors can even take on a game-like character with learners being able to run through a variety of scenarios while internalizing the presented factors and feedback loops (Baume, 2009). Moreover, coupled with the quantitative nature of these models, such software may transcend ordinary learning purposes by enabling decision-makers to run concrete SD simulations of different variable configurations, each representing a certain set of managerial policies.

Despite these tremendous capabilities, employing SD for devising BPC learning offerings brings forth some difficulties. Firstly, the coding of the vast amounts of realworld experiences is time and resource consuming and requires skilled personnel. Even though the goal is to mitigate subjective influences, the identification of impact factors and the elicitation and evaluation of relationships is bound to be subject to a certain degree of personal interpretation during the coding process. Further, in order to arrive at a usable model, information has to be aggregated and details omitted during the process, which results in a simplified representation of reality. Similarly, any quantification of relationships enabled by the resulting SD simulation models may naturally only be approximations of a real project environment. 
We contribute to the domain of BPC by making the abundance of case studies on BPC projects available to SD modeling. We have shown that SD is an appropriate methodology for reviewing and consolidating the complex and often non-linear findings from BPC case studies for learning purposes. By suggesting SD as an effective instrument to illustrate, explain, and convey the complex relationships between important variables in BPC projects, we contribute to the domains of knowledge management and learning. When controlled manipulation of the actual system (i.e. project environment) itself is unfeasible due to time, cost, moral or other considerations, the proposed approach can serve as a framework for assessing the implications of different managerial policies and procedures. The current lack of BPC SD simulation models in both literature and practice should make for a fertile ground in the BPC community with many practitioners eager to obtain non-committal means of experimentation, testing and scenario planning.

In addition to laying the groundwork for an empirically supported system dynamics approach in BPC, this paper extends the theory of BPC by identifying factors impacting employee morale in BPC projects as well as identifying relationships among these factors. This is a useful beginning in helping practitioners obtain a better understanding of managing employee morale in BPC projects. We expect potential future use of such modeling techniques for learning and simulation purposes to have a positive impact on BPC success rates in general.

Our findings establish various needs and possibilities regarding future research. While we found the dependent variable employee morale to be of crucial importance to the success of BPC projects, the complex nature of the considered environments calls for an extension of the model by accounting for further dependent variables. The feasibility of these models should be tested in learning environments comprised of practitioners and students. Feedback pertaining to the understandability, comprehensiveness and intuitiveness of the resulting learning tools may be used to improve both the models themselves and the software simulations making the models accessible to the learner. Further, the model should be tested in research for formulating and testing different hypotheses as well as in practice as a group decision-making tool for managers.

\section{Conclusion}

The focus of this research was to explore the usefulness of SD for consolidating the findings from case studies and conveying the structure and dynamics of BPC projects. As a means of demonstration and exploration, we developed a SD simulation model for effectively managing and understanding employee morale in BPC projects. The model was designed on the basis of empirical information gathered through a set of 65 case studies. Incorporating data from real-world applications, we elicited impact factors and their relationships among each other. The resulting model strives to comprehensively capture dynamic characteristics and nonlinearities of BPC projects with an emphasis on the management of employee morale. Maybe most importantly, the employed approach cogently demonstrates the benefits of $\mathrm{SD}$ as a way to review and consolidate the abundance of BPC case studies.

Our findings can help to facilitate learning processes in BPC project environments and lay the groundwork for SD model simulations allowing practitioners to analyze different scenarios with minimized resources and free of risk. Future research may build on this in order to craft learning environments and powerful simulation applications, which enable organizations to efficiently allocate their resources in the course of BPC projects, subsequently reducing failure rates and maximizing benefits. 


\section{References}

Akkermans, H., \& Dellaert, N. (2005). The dynamics of supply chains and networks. System Dynamics Review, 21(3), 173-186.

Albizu, E., Olazaran, M., \& Simon, K. (2004). BPR and change management: A case study of a large spanish electricity company. International Journal of Innovation Management, 8(4), 355-379.

Anderson, E. G. J., Morrice, D. J., \& Lundeen, G. (2003). The "physics" of capacity and backlog management in service and custom manufacturing supply chains. System Dynamics Review, 21(3), 217-247.

Ashayeri, J., Keij, R., \& Broeker, A. (1998). Global business process re-engineering: A system dynamics-based approach. International Journal of Operations \& Production Management, 18(9/10), 817-831.

Baguma, I., \& Ssewanyana, J. K. (2008). A simulation modelling-based investigation of the impact of IT infrastructure on business process reengineering. International Journal of Computing and ICT Research, 1(1), 8-20.

Barlas, Y., \& Diker, V. G. (2000). A dynamic simulation game (UNIGAME) for strategic university management. Simulation \& Gaming, 31(3), 331-358.

Baume, M. (2009). Computerunterstützte Planspiele für das Informationsmanagement: Realitätsnahe und praxisorientierte Ausbildung in der universitären Lehre am Beispiel der "CIO-Simulation”. Norderstedt: BoD - Books on Demand.

Bucher, T., \& Winter, R. (2007). Realisierungsformen des Geschäftsprozessmanagements - Eine explorative Klassifikationsanalyse. Proceedings of Wirtschaftinformatik 2007 (pp. 695-712).

Burges, T. F. (1998). Modelling the impact of reengineering with system dynamics. International Journal of Operations \& Production Management, 18(9/10), 950-963.

Caron, J. R., Stoddard, D. B., \& Jarvenpaa, S. L. (1994). Business reengineering at CIGNA corporation: Experiences and lessons learned from the first five years. MIS Quarterly, 18(3), 233-250.

Caulfield, C. W., \& Maj, S. P. (2002). A case for system dynamics. Global Journal of Engineering Education, 6(1), 25-34.

Cooper, K. G., \& Reichelt, K. S. (2004). Project changes: Sources, impacts, mitigation, pricing, litigation, and excellence. In P. W. G. Morris \& J. K. Pinto (Eds.), The Wiley Guide to Managing Projects (pp. 743-772). Wiley, Hoboken, NJ.

Davenport, T. H. (1993). Process innovation - Reengineering work through information technology. Harvard Business School Press, Boston, MA.

Dignan, W. (1995). Business process re-engineering at the co-operative bank: improving personal customer service. Total Quality Management, 7(1), 42-45.

Doyle, J. K., \& Ford, D. N. (1998). Mental models concepts for system dynamics research. System Dynamics Review, 14(1), 3-30.

Eden, C. E., Williams, T. M., \& Ackermann, F. A. (1998). Dismantling the learning curve: The role of disruptions on the planning of development projects. International Journal of Project Management, 16(3), 131-138.

Forrester, J. W. (1961). Industrial dynamics. Productivity Press, Portland, OR.

Forrester, J. W. (1976). Educational implications of responses to system dynamics models. In C. W. Churchman \& R. O. Mason (Eds.), World Modeling: a Dialog (pp. 27-35). American Elsevier, New York, NY.

Forrester, J. W. (1985). "The" model versus a modeling "process". System Dynamics Review, 1(1), 133-134.

Forrester, J. W. (1992). Policies, decisions, and information sources for modeling. European Journal of Operational Research, 59(1), 42-63.

Forrester, J. W. (1994). Learning through system dynamics as preparation for the 21 st 
century. Keynote address for system thinking and dynamic modeling conference for K-12 education at Concord Academy Concord, MA, USA.

Forrester, J. W., \& Senge, P. M. (1980). Tests for building confidence in system dynamics models. In A. A. Legasto (Eds.), Systems Dynamics: Studies in the Management Sciences (pp. 209-228). North-Holland, Amsterdam.

Gardiner, P. C., \& Ford, A. (1980). Which policy run is best, and who says so? In A. A. Legasto, J. W. Forrester, \& J. M. Lyneis (Eds.), System Dynamics: TIMS Studies in the Management Sciences (pp. 241-257) North-Holland, Amsterdam.

Geier, C. (1997). Ein Modell zur Nutzenbeurteilung des Einsatzes von Informationstechnologien im Rahmen der Prozeßgestaltung bei Business Process Reengineering-Projekten. PhD Thesis, Technische Universität München.

Graham, A. K., Morecroft, J. D. W., Senge, P. M., \& Sterman, J. D. (1992). Modelsupported case studies for management education. European Journal of Operational Research, 59(1), 151-166.

Greasley, A. (2009). A comparison of system dynamics and discrete event simulation. Proceedings of the Summer Computer Simulation Conference (pp. 83-87), Istanbul.

Grover, V. (1999). From business reengineering to business process change management: A longitudinal study of trends and practices. IEEE Transactions on Engineering Management, 46(1), 36-46.

Grover, V., Kettinger, W. J., \& Teng, J. (2000). Business process change in the 21st century. Business \& Economic Review, 46(2), 14-18.

Grover, V., \& Markus, L. (2008). Business process transformation. M.E. Sharpe, Armonk, NY.

Grover, V., Teng, J., Segars, A. H., \& Fiedler, K. (1998). The influence of information technology diffusion and business process change on perceived productivity: The IS executive's perspective. Information \& Management, 34(3), 141-159.

Guha, S., Grover, V., Kettinger, W. J., \& Teng, J. (1997). Business process change and organizational performance: Exploring an antecedent model. Journal of Management Information Systems, 14(1), 119-154.

Hammer, M. (1990). Reengineering work: Don't automate, obliterate. Harvard Business Review, 68(4), 104-112.

Hammer, M., \& Champy, J. (1993). Reengineering the corporation - A manifesto for business revolution. Harper Collins, New York, NY..

Harvey, D. (1994). Re-engineering: The critical success factors. McGraw Hill, New York, NY.

Hill, J. B., \& McCoy, D. W. (2011). Key issues for business process management 2011. Gartner, Inc. Business.

Hlupic, V., de Vreede, G., \& Orsoni, A. (2006). Modelling and simulation techniques for business processes analysis and re-engineering. International Journal of Simulation Systems, Science and Technology, 7(4), 1-8.

Howick, S., \& Eden, C. (2001). The impact of disruption and delay when compressing large projects: Going for incentives? Journal of the Operational Research Society, 52(1), 26-34.

Huizing, A., Koster, E., \& Bouman, W. I. M. (1997). Balance in business reengineering: An empirical study of fit and performance. Journal of Management Information Systems, 14(1), 93-118.

Jackson, S. (1995). Re-engineering the post office. New Technology, Work and Employment, 10(2), 142-146.

Jahangirian, M., Eldabi, T., Naseer, A., Stergioulas, L. K., \& Young, T. (2010). Simulation in manufacturing and business: A review. European Journal of Operational Research, 203(1), 1-13. 
Jauch, L. R., Osborn, R. N., \& Martin, T. N. (1980). Structured content analysis of cases: A complementary method for organizational research. The Academy of Management Review, 5(4), 517-525.

Jurisch, M. C., Cuno, J., Palka, W., Wolf, P., \& Krcmar, H. (2012). An integrative model of IT-enabled business process change: Causal structures in theory, research and practice. Proceedings of Hawaii International Conference on System Sciences (pp. 4297-4306), Maui, HI.

Karimi, J., Somers, T., \& Bhattacherjee, A. (2007). The impact of ERP implementation on business process outcomes: A Factor-Based Study. Journal of Management Information Systems, 24(1), 101-134.

Kettinger, W. J., \& Grover, V. (1995). Special section: Toward a theory of business process change management. Journal of Management Information Systems, 12(1), 930.

Kettinger, W. J., Teng, J., \& Guha, S. (1997). Business process change: A study of methodologies, techniques, and tools. MIS Quarterly, 21(1), 55-80.

Koch, S. (2011). Einführung in das Management von Geschäftsprozessen. Springer, Berlin, Heidelberg.

Konstantinidis, C., Kienegger, H., Flormann, L., Wittges, H., \& Krcmar, H. (2012). SAP Business ByDesign - Anpassung und Integration. Bonn: SAP PRESS.

Krippendorf, K. (1980). Content analysis: An introduction to its methodology. Sage Publications, Newbury Park, CA.

Lacity, M. C., Khan, S., Yan, A., \& Willcocks, L. (2010). A review of the IT outsourcing empirical literature and future research directions. Journal of Information Technology, $25,395-433$.

Larsen, M., \& Myers, M. (1997). BPR success or failure? A business process reengineering project in the financial services industry. Proceedings of International Conference on Information Systems (pp. 367-382), Atlanta, GA.

Larsson, R. (1993). Case survey methodology: Quantitative analysis of patterns across case studies. The Academy of Management Journal, 36(6), 1515-1546.

Lopez, J. (2011). Executive advisory: In comparing gartner' s board, CEO and CIO surveys, CIOs take last year' s challenge and build for growth. Gartner, Inc. Analysis.

Lucas, W. A. (1974). The case survey method: Aggregating case experience. Rand, Santa Monica, CA.

Lyneis, J., Cooper, K. G., \& Els, S. A. (2001). Strategic management of complex projects: A case study using system dynamics. System Dynamics Review, 17(3), 237-260.

Lämsä, A. M., \& Pucetaite, R. (2006). Developing of organizational trust among employees from a contextual perspective. Business Ethics: A European Review, 15(2), $130-141$.

Madachy, R. (2008). Software process dynamics. Wiley, Hoboken, NJ.

McAdam, R., \& Donaghy, J. (1999). A study of staff perceptions and critical business process re-engineering in the public sector. Business Process Management Journal, $5(1), 33-49$.

Melville, N., Kraemer, K. L., \& Gurbaxani, V. (2004). Information technology and organizational performance: An integrative model of IT business value. MIS Quarterly, 28(2), 283-322.

Morecraft, J. (1982). A critical review of diagramming tools for conceptualizing feedback models. Dynamica, 8(1), 20-29.

Newman, K., Cowling, A., \& Leigh, S. (1998). Case study: Service quality, business process re-engineering and human resources: A case in point? International Journal of Bank Marketing, 16(6), 225-242.

Paper, D. (1997): The value of creativity in business process re-engineering. Business Process Management Journal, 3(3), 218-231. 
Park, M., \& Pena-Mora, F. (2003). Dynamic change management for construction: Introducing the change cycle into model-based project management. System Dynamics Review, 19(3), 213-242.

Proctor, T., \& Gray, L. (2006). Business process re-engineering in the public sector: A case study. Euromed Journal of Business, 1(1), 84-97.

Quaddus, M., \& Intrapairot, A. (2001). Management policies and the diffusion of data warehouse: A case study using system dynamics-based decision support system. Decision Support Systems, 31(2), 223-240.

Radhakrishnan, A., Zu, X., \& Grover, V. (2008). A process-oriented perspective on differential business value creation by information technology: An empirical investigation. Omega, 36(6), 1105-1125.

Schwaninger, M., \& Hamann, T. K. (2005). Theory-Building with system dynamics: Principles and practices. Lecture Notes in Computer Science, 3643, 56-62.

Senge, P. M. (1990). The fifth discipline. New York, NY: Broadway Business.

Shannon, R. E. (1975). Systems simulation: The art and the science. Prentice-Hall, Englewood Cliffs, NJ.

Sioutine, A. V., \& Spector, J. M. (1999). On time, within budget: A simulation based learning environment for practising resource allocation in instructional systems development projects. Proceedings of the EUROMEDIA'99 Conference, Munich.

Skerlavaj, M., Stemberger, M. I., Skrinjar, R., \& Dimovski, V. (2007). Organizational learning culture: The missing link between business process change and organizational performance. International Journal of Production Economics, 106(2), 346-367.

Soh, C., \& Markus, M. L. (1995). How IT creates business value: A process theory synthesis. Proceedings of International Conference on Information Systems (pp. 2941), Amsterdam, Netherlands.

Spector, D. (2000). Rational debate and one-dimensional conflict. The Quarterly Journal of Economics, 115(1), 181-200.

Spector, J. M., \& Davidsen, P. I. (1997). Creating engaging courseware using system dynamics. Computers in Human Behavior, 13(2), 127-155.

Spengler, T., \& Schroeter, M. (2003). Strategic management of spare parts in closed-loop supply chains: A system dynamics approach. Interfaces, 33(6), 7-17.

Stemberger, M. I., Kovacic, A., \& Jaklic, J. (2007). A methodology for increasing business process maturity in public sector. Interdisciplinary Journal of Information, Knowledge, and Management, 2, 119-133.

Sterman, J. D. (1987). Testing behavioral simulation models by direct experiment. Management Science, 33(12), 1572-1592.

Sterman, J. D. (2000). Business dynamics: Systems thinking and modeling for a complex world. McGraw-Hill, Boston, MA.

Taylor, T., \& Ford, D. N. (2006). Tipping point dynamics in development projects. System Dynamics Review, 22(1), 51-71.

Teng, J., Fiedler, K. D., \& Grover, V. (1998). An exploratory study of the influence of the IS function and organizational context on business process reengineering project initiatives. Omega, 26(6), 679-698.

Thong, J. Y. L., Yap, C. S., \& Seah, K. L. (2000). Business process reengineering in the public sector: The case of the housing development board in Singapore. Journal of Management Information Systems, 17(1), 245-270.

Trkman, P. (2010). The critical success factors of business process management. International Journal of Information Management, 30(2), 125-134.

van Ackere, A., Larsen, E. R., \& Morecroft, J. D. W. (1993). Systems thinking and business process redesign: An application to the beer game. European Management 
Journal, 11(4), 412-423.

Vergidis, K., Tiwari, A., \& Majeed, B. (2006). Business process improvement using multi-objective optimization. BT Technology Journal, 24(2), 229-242.

Wang, L. C., \& Chen, M. P. (2012). The effects of learning style and gender consciousness on novices' learning from playing educational games. Knowledge Management \& E-Learning: An International Journal, 4(1), 63-77.

Weise, J. (1996). Durch Wandel voraus, der Change-Prozess bei der Deutschen Shell AG (DSAG). In M. Perlitz (Ed.), Reengineering zwischen Anspruch und Wirklichkeit, ein Management Ansatz auf dem Prüfstand (pp. 15-33). Gabler, Wiesbaden.

Xirogiannis, G., \& Glykas, M. (2004). Fuzzy cognitive maps in business analysis and performance: Driven change. IEEE Transactions on Engineering Management, 51(3), 334-351.

Yamamoto, T. (2010). A proposal for measuring interactivity that brings learning effectivness. Knowledge Management \& E-Learning: An International Journal, 2(1), 6-16.

Yin, R. K., \& Heald, K. (1975). Using the case survey method to analyze policy studies. Administrative Science Quarterly, 20(3), 371-381. 